\title{
Lichen planus pigmentosus
}

\section{Ouiame El Jouari, Ghita Senhaji, Salim Gallouj, Hanane Baybay, Fatima Zahra Mernissi}

\author{
Department of Dermatology, University Hospital Hassan II, Fez, Morocco
}

Corresponding author: Dr. Ouiame El Jouari, E-mail: eljouariouiame@gmail.com

Sir,

Lichen planus pigmentosus is considered a rare variant of lichen planus. It occurs in both sexes but shows a female preponderance. It is characterized by acquired dark brown to gray macular pigmentation located on sun - exposed areas. The dermoscopy and histology help to confirm the diagnosis. It is a disease which is basically recalcitrant to treatment and therapies attempted in this disorder are quite ineffective.

A 54-year-old dark-skinned postmenopausal woman presented with 3 years' history of itchy pigmented lesion of the face and lower limbs. On examination, large pigmented cupboards of the face and neckline (Fig. 1), as well as, multiple well-defined dark brown plates of varying size located on the legs (Fig. 2), were observed. Examination of the mucous membranes, nails and scalp was normal. The pull test was negative. Dermoscopical examination objectified multiples rosettes, whitish scales, and brown perifollicular hyperpigmentation (Fig. 3). A skin biopsy was performed. The histological examination showed an atrophic epidermis with hypergranulosis, band-like lymphocytic infiltrate of the upper dermis with abundant colloid bodies, and marked pigmentary incontinence. These findings were suggestive of lichen plan pigmentosus (Fig. 4). The patient was treated by topical steroids, depigmenting cream, associated to hydroxychloroquine $400 \mathrm{mg} /$ day and strict photoprotection. At follow-up visits, the pigmented lesions became lighter after 9 months and the decline is 12 months.

Lichen planus pigmentosus is considered a rare variant of lichen planus [1]. It is essentially a disease of the adult starting insidiously after the age of 30 . It occurs in both sexes but shows a female preponderance. It has been reported to occur predominantly in people with darker skin [2]. Pathogenesis represented by an altered

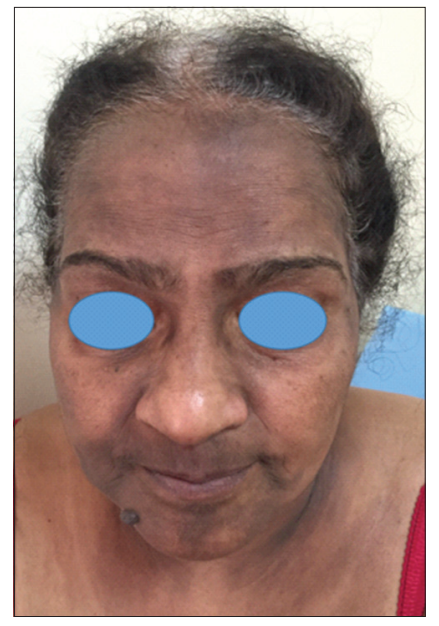

Figure 1: Large pigmented cupboards of the face and neckline.

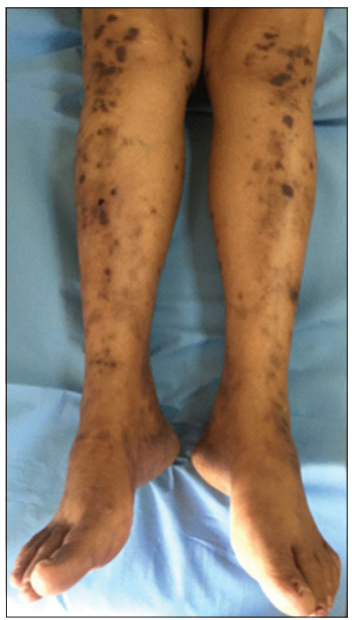

Figure 2: Multiple dark brown plaques of the legs.

cellular immune response mediated by T lymphocytes, in which CD8 + T lymphocytes recognize and attack epidermal keratinocytes, causing intense pigmentary incontinence. It is characterized by acquired dark brown to gray macular pigmentation located on sun- exposed areas of the face, neck, and flexures, commonly found in dark-skinned patients [1]. The dermoscopy 


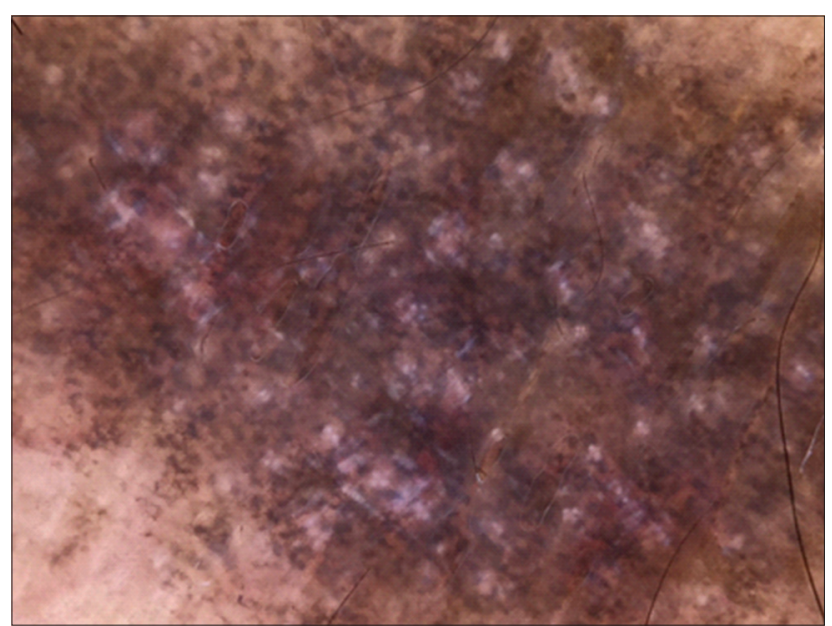

Figure 3: Dermoscopy showing rosettes, hyperkeratosis, and blue-grey perifollicular hyperpigmentation.

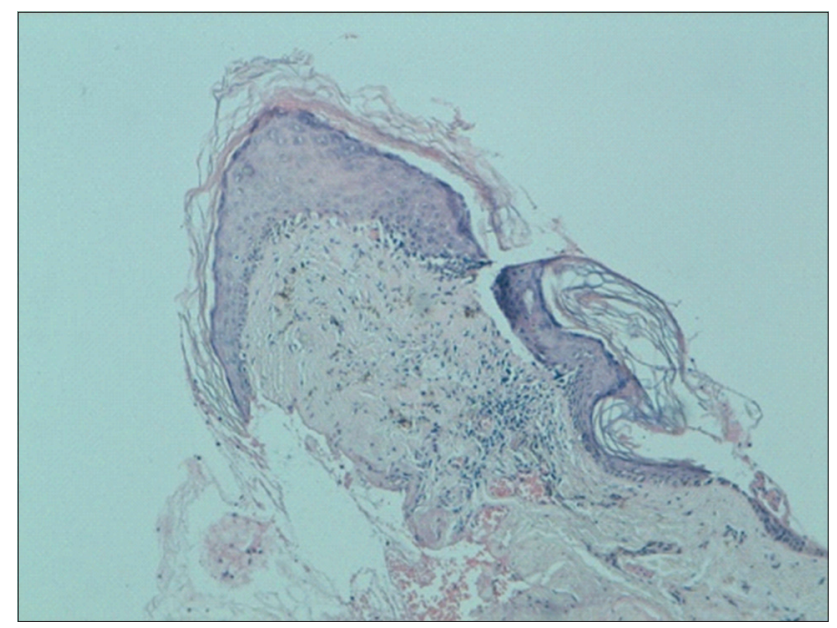

Figure 4: Histopathologic findings: focal interface dermatitis with superficial dermal melanosis and pigmentary incontinence.

of lichen plan pigmentosus can reveal reduction of the follicular openings, follicular hyperkeratosis, keratotic plugs, perifollicular erythema, white dots, interfollicular vessels with single loops, arborizing vessels and pigment network. Blue-grey structures in an annular or speckled pattern can also be found [3]. Erythema dyschromicum perstans is considered as the principal differential diagnosis of lichen plan pigmentosus. Other differentials are fixed drug eruption, macular amyloidosis, urticaria-pigmentosa, tar melanosis, frictional melanosis, berloque dermatitis, pigmented cosmetic dermatitis (Reihl's melanosis), postinflammatory hyperpigmentation, and idiopathic eruptive macular pigmentation and hyperpigmentation due to drugs and heavy metals [4]. Moreover, it may be associated with other disorders such as hepatitis $\mathrm{C}$ virus-induced liver disease, endocrinopathies, and autoimmune diseases as well as other variants of lichen planus and its sequelae [5]. Histopathology inclue perifollicular hyperkeratosis, atrophy with hydropic or vacuolar degeneration of the basal layer of the epidermis and scarce lymphohistiocytic or lichenoid infiltrates along the dermis, with pigmentary incontinence and the presence of melanophages [6]. Lichen plan pigmentosus is a disease which is basically recalcitrant to treatment and therapies attempted in this disorder are quite ineffective [4]. The management includes the use of topical medications such as steroids, immunomodulators, keratolytics, hydroquinone with or without retinoic acid, azelaic acid, kojic acid, glycolic acid, vitamin A, aqueous solution of $10 \%$ dimethylsulfoxide, among others, with variable results. There are favorable recent reports of the use of Nd: YAG laser, intense pulsed light and dermabrasion [3].

\section{Consent}

The examination of the patient was conducted according to the Declaration of Helsinki principles.

\section{REFERENCES}

1. Robles-Méndez JC, Rizo-Frías P, Herz-Ruelas ME, Pandya AG, Ocampo Candiani J. Lichen planus pigmentosus and its variants: review and update. Int J Dermatol. 2018;57:505-14.

2. Kanwar AJ, Dogra S, Handa S, Parsad D, Radotra BD. A study of 124 Indian patients with lichen planus pigmentosus. Clin Exp Dermatol. 2003;28:481-5.

3. Mulinari-Brenner FA, Guilherme MR, Peretti MC, Werner B. Frontal fibrosing alopecia and lichen planus pigmentosus: diagnosis and therapeutic challenge. An Bras Dermatol. 2017;92(5 Suppl 1):79-81.

4. Ghosh A, Coondoo A. Lichen planus pigmentosus. Indian J Dermatol. 2016;61:482-6.

5. Al-Mutairi N, El-Khalawany M. Clinicopathological characteristics of lichen planus pigmentosus and its response to tacrolimus ointment: an open label, non-randomized, prospective study. J Eur Acad Dermatol Venereol. 2010;24:535-40.

6. Das A, Mishra V, Podder I, Kumar P, Das D, Das NK. Linear lichen planus pigmentosus: A rare entity with an illusory presentation. Pigment Int. 2014;1:100-2.

Copyright by Ouiame El Jouari, et al. This is an open-access article distributed under the terms of the Creative Commons Attribution License, which permits unrestricted use, distribution, and reproduction in any medium, provided the original author and source are credited.

Source of Support: Nil, Conflict of Interest: None declared. 